\title{
PERCEPÇÕES DE AGRICULTORES FAMILIARES E TÉCNICOS DA REGIÃO DO VALE DO RIBEIRA (SP) SOBRE O MERCADO INSTITUCIONAL
}

\author{
Tiago Tomaz Gomes ${ }^{1}$ \\ Lucimar Santiago de Abreu²
}

\begin{abstract}
RESUMO
Em diversos territórios do país os produtos da agricultura familiar apresentam dificuldades de inserção da produção nos mercados, com vistas a solucionar essa problemática, nas últimas décadas, um conjunto de políticas foi criado para o setor, denominadas, mercado institucional de alimentos da agricultura familiar ou PAA e PNAE, também, aplicada à região do Vale do Ribeira (SP). O objetivo da pesquisa foi analisar as percepções de produtores familiares e técnicos, associadas à política de compra institucional, no Vale do Ribeira (SP) e seus impactos sociais. A metodologia caracteriza-se pela natureza qualitativa, dialógica e participativa. Direcionando a observação no campo, a construção de entrevistas, a aplicação, além da análise do material. Os resultados mostram que os programas teriam potencial para impactar positivamente a realidade desses agricultores, mas essa política apresentou limitações quanto ao alcance do público-alvo (agricultores familiares da região da área do estudo). Um dos pontos apontados foi a falta de informação e de compreensão do funcionamento operacional do programa, além de ficar clara a necessidade de assistência técnica qualificada, no campo da agricultura de base ecológica.
\end{abstract}

Palavras-chave: agricultura familiar; práticas ecológicas ou orgânicas; políticas públicas.

\section{PERCEPTIONS OF FAMILY FARMERS AND TECHNICIANS IN THE RIBEIRA VALLEY REGION ABOUT THE INSTITUTIONAL MARKET}

\begin{abstract}
In several areas of the country, the products of family farming present difficulties in the insertion in the markets. In order to solve this problem, in the last decades, a set of policies was created for the sector, denominated, institutional market of food of family farming or PAA and PNAE, also applied to the region of Vale do Ribeira (SP). The objective of the research was to analyze the perceptions of family farming and technicians, associated with the institutional purchasing policy, in Vale do Ribeira (SP) and its social impacts. The methodology was characterized by its qualitative,

\footnotetext{
${ }^{1}$ Graduado em Agronomia. Mestrado em Agroecologia e Desenvolvimento Rural (UFSCar) em Araras, SP. E-mail: tiago_chunda@hotmail.com

2 Graduada em Agronomia (FEAB). Mestrado em Sociologia (UNICAMP). Doutora em Ciências Sociais (UNICAMP). Pesquisadora da Embrapa Meio Ambiente. Professora Colaboradora do Programa de Pósgraduação em Agroecologia e Desenvolvimento Rural da Universidade Federal de São Carlos (UFSCar) em Araras, SP. E-mail: lucimar.abreu@embrapa.br
} 
dialogical and participatory nature. It focuses on observation in the field, construction of interviews, application, and analysis of the material. The results show that the programs would have the potential to positively affect the reality of these farmers, but this policy presented limitations as to the reach of the target audience (family farmers in the region of the study area). One of the obstacles pointed out was the lack of information and understanding of the operational functioning of the program, due to lack of qualified technical assistance in the field of ecological-based agriculture.

Key words: family farming; ecological or organic practices; public policies.

\section{INTRODUÇÃO}

A agricultura familiar é um segmento social e econômico de importância estratégica para o Brasil, tendo papel central na segurança alimentar, na conservação ambiental, na geração de emprego e renda em áreas rurais. No contexto internacional, e talvez ainda mais no Brasil - onde essa questão do papel e do lugar da unidade de produção familiar é particularmente importante -, é necessário entender o conceito de agricultura familiar. O que é a agricultura familiar? Trata-se de uma forma social heterogênea cujas unidades de produção se diferenciam pela sua diversidade e pela capacidade do agricultor de se apropriar dos meios de produção e desenvolvê-los. A organização da produção e do trabalho fica a cargo do produtor e de sua família, e o trabalho assalariado, quando ocorre, é apenas complementar. (ABREU, 2005)

De acordo com Lamarche (1993, p.19, apud Abreu, 2005, p.36), "no campo da agricultura familiar, o termo produção familiar recobre situações extremamente variadas e diferentes, e se define a partir de um maior ou menor grau de integração com a sociedade econômica, tanto sob o plano técnico-econômico quanto em relação ao plano sociocultural. Um determinado grau de integração à sociedade econômica corresponde a uma determinada relação com a sociedade de consumo, um determinado modo de vida" e, é também, um determinado modo de percepção. Assim, a consideração desses elementos permite que a abordagem dê conta dessa dupla dimensão da unidade de exploração familiar.

A coexistência de diversos estilos de funcionamento demonstra que a unidade de produção familiar não pode ser definida em uma forma de produção específica, devem ser levadas em consideração, condições de bloqueio ou de ruptura, que Ihes permitem ou não colocar em prática as estratégias para atingir seus objetivos.

Apesar da relevância da agricultura familiar, historicamente esse setor permaneceu por um longo período invisível e marginal, devido à falta de reconhecimento institucional e político do seu papel econômico e social. Isso começa a mudar na década de 90, com o surgimento do Programa Nacional de Fortalecimento da Agricultura Familiar (PRONAF) e, de outras políticas públicas específicas para o setor, nas décadas seguintes (MATTEI, 2014).

Dentre essas políticas destacam-se àquelas direcionadas a compra de alimentos institucional da agricultura familiar. Na esfera federal (dois) programas são implantados em maior escala, o Programa de Aquisição de Alimentos (PAA) e o Programa Nacional de Alimentação Escolar (PNAE). Esses programas abrangem o território nacional, onde a presença de agricultura familiar é identificada. $O$ Vale do Ribeira, no Estado de São Paulo, área da pesquisa, é um dos territórios com índices baixos de desenvolvimento econômico e social, mas com uma expressiva riqueza ecológica e sociocultural, diretamente relacionada à forma de ocupação humana da região (ABREU, 2005). 
Diante desse contexto surgem algumas questões de pesquisa, tais como: Quais são os impactos sociais e econômicos promovidos pelos programas de compra institucional PAA e PNAE no âmbito dos agricultores selecionados para a pesquisa?

E ainda, quais são os acertos e falhas na operação dessas políticas na região? $\mathrm{E}$ especialmente como esses impactos positivos ou negativos são percebidos por atores locais (produtores e técnicos de desenvolvimento) participantes dos programas PAA e PNAE, e em que medida essas percepções interferem na condução e impactos dos programas.

O objetivo da pesquisa foi analisar as percepções de atores chaves, a respeito da política do mercado institucional. Para tanto, buscou se identificar, caracterizar e descrever o desenvolvimento da agricultura familiar no Vale do Ribeira e, seus impactos principais decorrentes do acesso ao PAA e PNAE. Adotou-se a abordagem dialógica, a escolha do universo da pesquisa teve como critério orientador a diversidade ecológica e agrícola (sistemas de produção) social e econômica, portanto, diversas dimensões são articuladas, característica da pesquisa multidisciplinar.

Dada à abrangência do tema (envolve políticas públicas, agricultura familiar e transição agroecológica) e, o limite de espaço, o recorte deste artigo privilegiou discutir políticas públicas e agricultura familiar no Brasil, com foco na discussão dos programas PAA e PNAE, seguida da caracterização do local da pesquisa e da metodologia da pesquisa, sem adentrar na questão, da transição agroecológica propriamente dita.

\section{BALANÇO GERAL DAS POLÍTICAS PÚBLICAS PARA AGRICULTURA FAMILIAR}

A agricultura familiar é representada por um universo de quase 4,5 milhões de estabelecimentos (IBGE, 2006) que obtém a subsistência de suas atividades produtivas, a agricultura familiar é responsável pela produção da maior parte de alguns dos principais gêneros alimentícios consumidos pela população brasileira como, mandioca, feijão, leite, carne suína, entre outros (IBGE, 2006), exercendo papel fundamental para a soberania alimentar da sociedade brasileira, além da geração de empregos e rendas (IBGE, 2006).

Outro fato de extrema importância, dada à crise ambiental de proporções globais que enfrenta a humanidade, destaca-se a capacidade de preservação e uso sustentável dos recursos naturais e da biodiversidade encontrada na agricultura familiar. Alguns autores colocam que, sob o prisma da estabilidade, resiliência e equidade, são muitas as vantagens apresentadas pela organização familiar, devido à sua ênfase na diversificação e na maleabilidade de seu processo decisório, acrescentando outros atributos como, uso de insumos internos, na durabilidade dos recursos naturais e na qualidade de vida, que evidenciam formas produtivas mais ecológicas (ALTIERI 1995); (VEIGA, 1996); (KAUFMANN; PASQUALOTTO, SENA, 2019).

O período anterior à década de 1990 foi negativo para o setor da agricultura familiar, já que ela permaneceu à margem dos benefícios e da construção das políticas públicas. Mas em meados da década mencionada, a agricultura familiar, tornou-se alvo das políticas brasileiras. Até então, não existiam políticas com abrangência nacional, voltadas ao atendimento específico deste segmento social (CAZELLA; MATTEI; SCHNEIDER, 2004). 
A nova trajetória para a agricultura familiar é iniciada, também, por influência da redemocratização e pela constituição de 1988, que através dos conselhos gestores de políticas setoriais e das políticas gerais de desenvolvimento, nas diversas esferas governamentais, estimula novos espaços de participação social e reconhece direitos sociais (MATTEI, 2014).

Quadro 01 - Principais leis e decretos relacionados à produção familiar e a políticas públicas entre 1996 - 2012

\begin{tabular}{|c|c|}
\hline Marco legal & Descrição \\
\hline $\begin{array}{l}\text { Decreto } \mathrm{n}^{\circ} 1.946 \text {, } \\
\text { de } 28 / 07 / 1996\end{array}$ & $\begin{array}{l}\text { Criação do PRONAF: Representa a legitimação, por parte do } \\
\text { Estado brasileiro, de uma nova categoria social, } \\
\text { desencadeando a emergência de outras políticas } \\
\text { diferenciadas de desenvolvimento rural. }\end{array}$ \\
\hline $\begin{array}{l}\text { Decreto } n^{\circ} 3.338 \\
\text { de14/01/2000 }\end{array}$ & Cria o Ministério do Desenvolvimento Agrário. \\
\hline $\begin{array}{l}\text { Lei } n^{0} 10.696, \text { de } \\
02 / 07 / 2003 \text {. }\end{array}$ & Artigo 19 - Cria o Programa de Aquisição de Alimentos \\
\hline $\begin{array}{l}\text { Decreto } n^{\circ} 5.033 \text {, } \\
\text { de } 05 / 04 / 2004 .\end{array}$ & $\begin{array}{l}\text { Regulamenta a estrutura regimental do Ministério do } \\
\text { Desenvolvimento Agrário }\end{array}$ \\
\hline $\begin{array}{l}\text { Lei no } 11.326 \text { de } \\
24 / 07 / 2006\end{array}$ & $\begin{array}{l}\text { Lei da Agricultura Familiar: Reconhece a categoria social e } \\
\text { estabelece os conceitos, princípios e instrumentos } \\
\text { destinados à formulação das políticas públicas para este } \\
\text { grupo social. }\end{array}$ \\
\hline $\begin{array}{l}\text { Decreto } n=11.503 \\
\text { de } 25 / 02 / 2008\end{array}$ & $\begin{array}{l}\text { Institui o Programa Territórios da Cidadania: Busca promover } \\
\text { e acelerar a superação da pobreza e das desigualdades } \\
\text { sociais no meio rural, através universalização de programas } \\
\text { básicos de cidadania, por meio de estratégia de } \\
\text { desenvolvimento territorial sustentável. }\end{array}$ \\
\hline $\begin{array}{l}\text { Lei } n^{\circ} 12.188 \\
\text { de } 11 / 01 / 2010\end{array}$ & $\begin{array}{l}\text { Cria a Política Nacional de Assistência Técnica e Extensão } \\
\text { Rural para a Agricultura Familiar e Reforma Agrária - } \\
\text { PNATER }\end{array}$ \\
\hline $\begin{array}{l}\text { Decreto no } 7.794 \text {, } \\
\text { de } 20 / 08 / 2012 \text {. }\end{array}$ & $\begin{array}{l}\text { Instituí a Política Nacional de Agroecologia e Produção Orgâ } \\
\text { nica - PNAPO, com o objetivo de integrar, articular e adequar } \\
\text { políticas, programas e ações indutoras da transição } \\
\text { agroecológica e da produção orgânica e de base } \\
\text { agroecológica. }\end{array}$ \\
\hline
\end{tabular}

Fonte: Documentos institucionais do quadro institucional e legal, elaborado pelos autores.

Assim, segundo Schmitt e Guimarães (2008), o papel das políticas de cunho social tem potencial para alavancar o desenvolvimento do espaço rural por meio da geração de renda e do trabalho. Nesse contexto os dois programas federais, PAA e o PNAE se destacam nacionalmente, em termos geográfico e social.

\section{PAA e PNAE}

Criado em 2003, o PAA foi concebido no bojo de um grupo de políticas estruturantes do Programa Fome Zero, sendo uma ação do Governo Federal para o enfrentamento da fome e da pobreza no Brasil, e o fortalecimento da agricultura familiar. Instituído pelo Art. 19 da Lei № 10.696, de 02 de julho de 2003, e 
regulamentada por diversos decretos, sendo que, o que está em vigência é o Decreto № 7.775, de quatro de julho de 2012.

O PAA é o programa de compra de alimentos da agricultura familiar, destinando-os à formação de estoques governamentais ou à doação para pessoas em situação de insegurança alimentar e nutricional, atendidas por programas sociais, além de facilitar o processo de comercialização local. Para isso, o programa utiliza mecanismos de comercialização que favorecem a aquisição direta de produtos de agricultores familiares ou de suas organizações, com dispensa de licitação, estimulando a agregação de valor à produção (BRASIL, 2017), através da aplicação de princípios da agroecologia em processos de transição agroecológica (ABREU et al., 2012).

A Lei no 11.947, de 16 de junho de 2009, "determina que no mínimo $30 \%$ do valor repassado a estados, municípios e Distrito Federal pelo Fundo Nacional de Desenvolvimento da Educação (FNDE) para o Programa Nacional de Alimentação Escolar (PNAE) deve ser utilizado na compra de gêneros alimentícios diretamente da agricultura familiar e do empreendedor familiar rural ou de suas organizações, priorizando-se os assentamentos da reforma agrária, as comunidades tradicionais indígenas e as comunidades quilombolas", ou portadores da Declaração de Aptidão do PRONAF (DAP). A DAP é um documento que reconhece legalmente os agricultores familiares (DAP Física) e suas organizações (DAP Jurídica). A aquisição dos produtos da Agricultura Familiar poderá ser realizada por meio da Chamada Pública, dispensando-se, nesse caso, o procedimento licitatório. De posse de um destes documentos, os agricultores têm acesso a programas e políticas públicas, entre as quais, o PAA e o PNAE.

O PAA é executado com recursos da Secretaria Especial de Agricultura Familiar e do Desenvolvimento Agrário (Sead) e do Ministério do Desenvolvimento Social (MDS), em parceria com estados, municípios e com a Companhia Nacional de Abastecimento (Conab). O programa possui cinco modalidades de operação que podem ser acessadas individualmente ou através das organizações dos agricultores. Todas modalidades apresentam limite anual de até $R \$ 8.000,00 /$ família. O fornecimento de produtos orgânicos é privilegiado sob o ponto de vista econômico, paga-se até $30 \%$ a mais do valor do alimento oriundo do cultivo em sistema convencional. Por tanto, além do papel social dos programas: merenda escolar, hospitais, formação de estoque e, promotor de renda familiar, o programa influencia a adesão do agricultor aos processos de transição agroecológica.

O PNAE, popularmente conhecido como merenda escolar teve sua origem no início da década de 1940, mas não foi concretizado, por alegação institucional de indisponibilidade de recursos financeiros. Na década de 1950, foi elaborado um abrangente Plano Nacional de Alimentação e Nutrição (PNAN). É nele que, pela primeira vez, se estrutura o programa de merenda escolar em âmbito nacional, sob responsabilidade pública. Passando por várias modificações e decretos, somente em 1979, é denominado PNAE (BRASIL, 2017).

O FNDE regula o programa e sua relação com a agricultura familiar. É definido que o limite individual de venda para o agricultor familiar na comercialização para o PNAE é de $\mathrm{R} \$ 20.000,00 /$ ano por entidade executora.

\section{CONTEXTO LOCAL DA PESQUISA: VALE DO RIBEIRA (SP)}

O Vale do Ribeira é uma região localizada ao sul do estado de São Paulo e a leste do estado do Paraná, abrangendo o território da bacia hidrográfica do Rio Ribeira de Iguape e o Complexo Estuarino Lagunar de Iguape-Cananéia-Paranaguá 
(Figura 1). A região possui área de 2.830 .666 hectares $\left(28.306 \mathrm{~km}^{2}\right)$, sendo 1.119.133 hectares no Paraná e 1.711.533 hectares em São Paulo, correspondendo a respectivamente $39,5 \%$ e 60,5\% em relação à área total da Bacia (ISA, 2008).

Figura 1 - Localização da região do Vale do Ribeira entre os estados de SP e PR

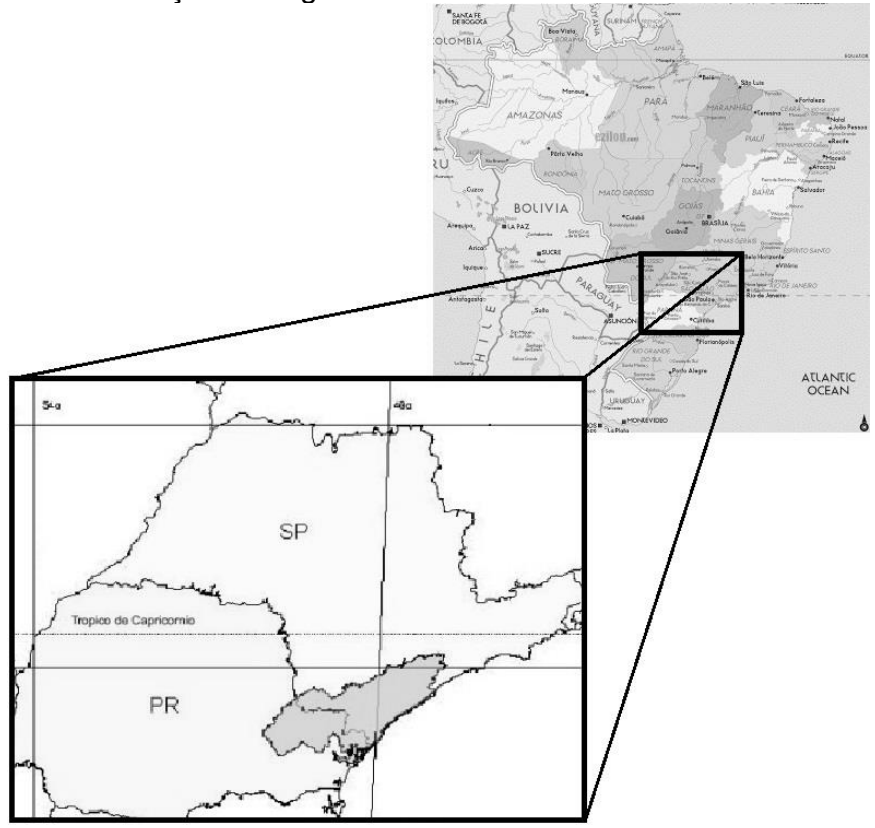

Fonte: Sistema de informações territoriais, MDA, adaptado pelos autores.

Apesar de sua localização privilegiada entre duas grandes metrópoles, os indicadores socioeconômicos e de qualidade de vida são valores fortemente baixos. A região é considerada a mais pobre dos dois Estados, fruto de situação histórica de abandono por parte do estado e do governo federal (SEMA, 1997). O Índice de Desenvolvimento Humano (IDH) de algumas cidades (Ribeira, Itaoca e Barra do Chapéu) com valores $(0,678,0,650$ e 0,646, respectivamente) situa-se abaixo de regiões brasileiras tidas como pobres, como a região Nordeste $(0,684)$ e Vale do Jequitinhonha/MG $(0,680)$ (PNUD, 2011).

O Vale do Ribeira integra a Reserva da Biosfera, portanto, é considerado pela Organização das Nações Unidas para a Educação, a Ciência e a Cultura (UNESCO), patrimônio da humanidade, sendo reconhecido internacionalmente por abrigar, o maior remanescente de Mata Atlântica, preservada no Brasil, sendo que, dos $7 \%$ que restam do bioma, em território nacional, $21 \%$ estão localizados na região.

Outro atributo da região é a forte presença de população rural. O Vale do Ribeira conta com uma população total de 443,231 habitantes, sendo 25,9\% de população rural (IBGE, 2010). Segundo a Fundação SEADE (2013), a taxa da população rural na porção paulista do Vale do Ribeira, no ano de 2010, era de $28,6 \%$ contra $4,1 \%$ no restante do estado. Estes dados destacam a elevada importância social do espaço rural desta região, em relação a outros territórios. Outro dado que acentua essa importância é a participação do setor agropecuário na 
economia, com uma taxa de $14,18 \%$ contra apenas $2,11 \%$ para o restante dos municípios do estado de São Paulo (SEADE, 2013).

$O$ Vale do Ribeira pode ser geomorfologicamente dividido em sub-regiões Baixo, Médio e Alto Vale. O Baixo Vale apresenta características voltadas ao ambiente litorâneo, tendo como limite a cidade de Eldorado. Já no Alto Vale, as características são voltadas à região do planalto, a cidade de Ribeira é geograficamente a área limite. O Médio Vale possui elementos da paisagem litorânea e planáltica, sendo um misto de ambas (ROBRAHN-GONZÁLEZ; BLASIS, 1998). Essa diferenciação é válida também para aspectos ecológicos, históricos, sociais e econômicos e, é naturalmente reconhecida pela população da região. Há, porém, lacunas na literatura no que se refere à descrição das três sub-regiões.

No que se refere ao campo de estudo, da pesquisa, buscou-se captar a diversidade, mencionadas das três sub-regiões. Neste sentido, a pesquisa de campo foi conduzida nos seguintes municípios: Apiaí e Barra do Chapéu (Alto Vale); Eldorado e Sete Barras (Médio Vale); Cananeia (Baixo Vale), todos na porção paulista do Vale do Ribeira.

Figura 2 - Municípios da pesquisa

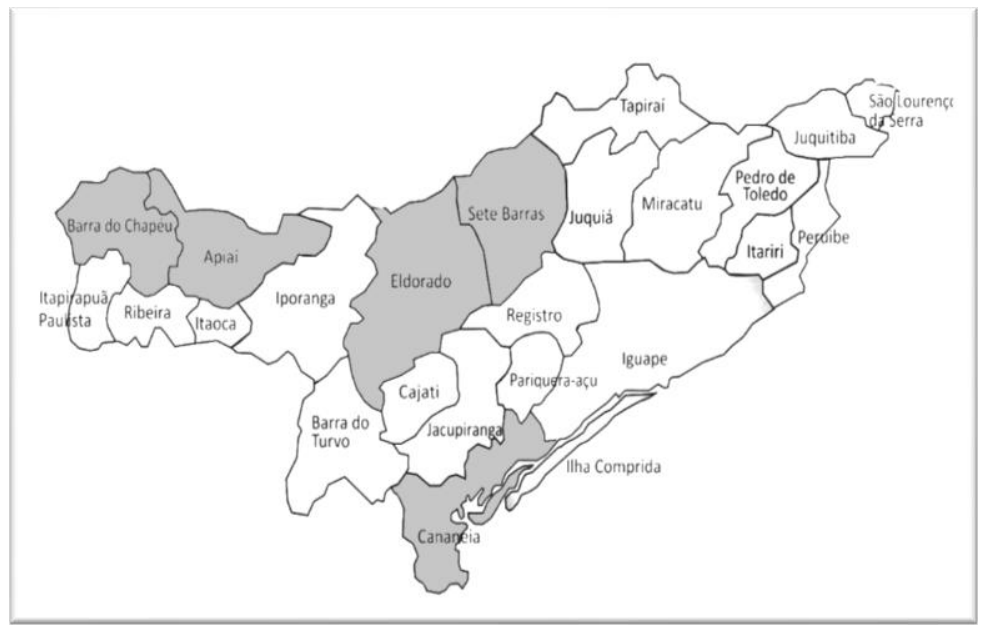

Fonte: Sistema geográfico de informações, MDA Adaptado pelos autores.

O perfil geral da população rural na região é caracterizado pela diversidade social, econômica e cultural da categoria abrangente "agricultores familiares", representados em sua maioria por agricultores tradicionais, presentes em todo o território; entre os quais, quilombolas, (ABREU, 2005). Vivem em maior concentração no Médio Vale nos municípios de Iporanga e Eldorado. Também foram identificados caiçaras, no Baixo Vale; além de indígenas, ribeirinhos, assentados e ainda, agricultores familiares de variadas origens, que há várias gerações habitam o território.

As produções nas microrregiões são em grande parte de subsistência e convivem com a produção convencional de bananas e palmito pupunha, em escala comercial. No Médio Vale, ocorre também, o cultivo de Pinus. Já a produção convencional de tomate, em escala comercial, é predominante no Alto Vale. A dificuldade de comercialização é um dos problemas mais relevantes enfrentados pelos agricultores familiares da região. Há casos que o escoamento da produção 
ocorria em grupo ou individualmente, ao longo do tempo quase que exclusivamente através de atravessadores, cujos compradores praticam preços baixos, além de não haver nenhuma garantia de compra da produção. Apesar destes atravessadores ainda serem operantes na compra da produção agrícola familiar, nos últimos anos os agricultores familiares da região tiveram acesso aos programas de compra institucional PAA e PNAE, que oferece melhores preços à produção, proporcionando uma nova experiência profissional para esses agricultores e comunidades.

À luz das questões mencionadas na introdução, a avaliação de políticas públicas é um processo provedor de conhecimento fundamental para o entendimento dos desafios e obstáculos do desenvolvimento, bem como dos possíveis caminhos para atingir os objetivos finais da política pública, que em seus princípios visam fortalecer esse segmento social da agricultura (COEHN e FRANCO, 1999).

Esse tipo de política pública criada nas últimas décadas carece de qualificação dos impactos sociais e econômicos gerados, e sendo o caso, de subsídios ou recomendações para o aprimoramento e a continuidade das ações.

\section{METODOLOGIA}

O método compreensivo de Max Weber (1999) define que ação social, é dotada de sentido, portanto, o autor busca desvendar o sentido da ação social, através da apreensão dos significados e dos valores sociocultural e econômico. Esse aporte teórico permite integrar técnicas participativas das ciências sociais, adaptadas e aplicadas para atender os objetivos desta investigação, à luz da realidade empírica. Assim, segue a descrição sucinta da metodologia.

$\mathrm{Na}$ primeira etapa da pesquisa, denominada exploratória - foi previsto a realização de entrevistas e a observação participante - através de visitas ao grupo de agricultores e técnicos para definição do universo social da pesquisa ABREU (2005).

A escolha do universo de atores ou amostra da pesquisa teve como critério captar a diversidade das situações, tal como aplicado por Abreu (2005), as quais representam a diversidade das condições sociais, econômicas, paisagens ecológicas e produtivas da região. Para construir a diversidade de situações foi necessário incorporar nas entrevistas atores sociais que residiam nas três subregiões, mencionadas. A definição do local da pesquisa teve suporte as experiências prévias de acompanhamento e assistência técnica, efetuada pelo primeiro autor do artigo e, igualmente, pela segunda autora na região, onde conduziu projetos anteriores de investigação científica (ABREU, 2005).

Incluiu também, a ação paralela de levantamento de informações e conhecimentos sobre a realidade local, baseada no levantamento de documentos, trabalhos científicos, dados do IBGE e, relatórios das instituições locais. O apoio de fontes bibliográficas sobre a temática foi crucial para considerar o estado atual do desenvolvimento científico do assunto. Além disto, esse momento de pesquisa visa também obter o conhecimento detalhado para a construção do roteiro das entrevistas

Em seguida, no processo de análise do material coletado foi aplicada a técnica da descrição densa inspirada na teoria social das ciências sociais weberiana, para compreender a situação produtiva e o processo de inserção no mercado, a operacionalização dos programas, os elementos associados às percepções e práticas do grupo social (produtores e técnicos, especificamente) em relação ao PAA e PNAE e ao desenvolvimento rural. Em relação, às questões éticas, um termo de consentimento livre por parte dos atores envolvidos foi produzido. 
As entrevistas foram aplicadas em nove agricultores familiares e dois técnicos que integram os lócus da pesquisa e da observação participante, operacionalizada em diversas visitas ao campo. Dois roteiros de entrevistas semiestruturadas foram elaborados. O roteiro adaptado para entrevistar os técnicos, continha dez questões abrangendo os seguintes temas: histórico e trajetória de vida; experiência na agricultura familiar e orgânica; percepção sobre a assistência técnica, mercados institucionais, comercialização e políticas públicas. O roteiro elaborado para os agricultores continha vinte e duas questões abrangendo os seguintes temas: histórico e trajetória; produção e meio ambiente; percepção da profissão agrícola; mercados e comercialização; políticas públicas; organizações sociais.

Foram realizadas nove entrevistas semiestruturadas com agricultores familiares e duas com técnicos, entre os meses de setembro de 2016 a julho de 2017. As entrevistas, anotadas e gravadas foram transcritas e analisadas. A interpretação compreensiva da realidade onde se insere os agricultores e de suas percepções levou em consideração questões que atuam no comportamento humano: 1. Sociocultural; 2. O ambiente ecológico e da produção agrícola; 3 . As influências do Estado (condições para produzir, como é o caso da assistência técnica, e o papel das políticas públicas); 4. A dimensão econômica. Enfim, elementos que influenciam o comportamento e ação dos atores sociais (ABREU, 2005).

\section{RESULTADOS E DISCUSSÃO}

\subsection{TRAJETÓRIA E EXPERIÊNCIA NA PRODUÇÃO FAMILIAR}

No início desta seção, apresenta-se, o perfil sociocultural dos entrevistados, - histórico familiar e suas experiências técnicas, com base nas entrevistas realizadas (Quadro 2 e 3). Em seguida, apresenta-se a caracterização dos sistemas de produção e, a descrição do processo de operacionalização do PAA e do PNAE nas localidades, avaliando como essas diversas dimensões reunidas dialogam com a percepção dos entrevistados. Em seguida, descrevem-se as experiências e percepções dos agricultores e de técnicos sobre o suporte em termos de assistência técnica e extensão rural.

Quadro 2 - Perfil social dos técnicos entrevistados

\begin{tabular}{|c|c|c|c|c|c|}
\hline $\begin{array}{c}\text { Ator } \\
\text { social }\end{array}$ & $\begin{array}{c}\text { Idade e } \\
\text { Gênero }\end{array}$ & $\begin{array}{c}\text { Escolaridad } \\
\text { e }\end{array}$ & $\begin{array}{c}\text { Experiência } \\
\text { técnica }\end{array}$ & $\begin{array}{c}\text { Histórico } \\
\text { Familiar e } \\
\text { Pessoal }\end{array}$ & $\begin{array}{c}\text { Ação } \\
\text { Profissional }\end{array}$ \\
\hline 1 & $52-\mathrm{M}$ & $\begin{array}{c}\text { Superior: } \\
\text { Engenheiro } \\
\text { Agrônomo }\end{array}$ & $\begin{array}{c}\text { Agricultura } \\
\text { familiar } \\
\text { ecológica. } \\
\text { Políticas } \\
\text { públicas. }\end{array}$ & $\begin{array}{c}\text { Origem } \\
\text { urbana - } \\
\text { Identidade } \\
- \text { Valores } \\
\text { ambientais } \\
\text { e sociais }\end{array}$ & $\begin{array}{c}\text { Vale do } \\
\text { Ribeira }\end{array}$ \\
\hline 2 & $33-\mathrm{M}$ & $\begin{array}{c}\text { Superior: } \\
\text { Antropólogo }\end{array}$ & $\begin{array}{c}\text { Cooperativismo } \\
\text { e políticas } \\
\text { públicas com } \\
\text { comunidades } \\
\text { tradicionais. }\end{array}$ & $\begin{array}{c}\text { Militância } \\
\text { MST. } \\
\text { Questão } \\
\text { indígena. }\end{array}$ & $\begin{array}{c}\text { Eldorado } \\
\text { (médio vale) }\end{array}$ \\
\hline
\end{tabular}

Fonte: Dados oriundos da pesquisa de campo (2017), conduzida pelos autores. 
No caso, específico dos atores técnicos, o critério de seleção da pesquisa foi à experiência e participação em programas do PAA e PNAE. Assim, foram escolhidos os que trabalhavam diretamente com agricultores familiares, agricultura orgânica e mercado institucional. Os dois profissionais são reconhecidos pelos atores sociais do território pela capacidade técnica e de gestão.

Quadro 3 - Perfil social de agricultores e agricultoras

\begin{tabular}{|c|c|c|c|c|c|}
\hline $\begin{array}{l}\text { Ator } \\
\text { es } \\
\text { soci } \\
\text { ais }\end{array}$ & $\begin{array}{l}\text { Idade e } \\
\text { Gênero }\end{array}$ & Escolaridade & $\begin{array}{c}\text { Experiência atual } \\
\text { técnica }\end{array}$ & $\begin{array}{l}\text { Histórico } \\
\text { Familiar e } \\
\text { Pessoal }\end{array}$ & $\begin{array}{c}\text { Ação } \\
\text { Profissional }\end{array}$ \\
\hline 1 & $49-\mathrm{F}$ & $\begin{array}{l}\text { Ensino médio } \\
\text { técnico }\end{array}$ & $\begin{array}{l}\text { Transição } \\
\text { orgânica e } \\
\text { agroflorestal }\end{array}$ & $\begin{array}{l}\text { Origem } \\
\text { portuguesa - } \\
\text { rural }\end{array}$ & $\begin{array}{l}\text { Eldorado } \\
\text { (médio vale) }\end{array}$ \\
\hline 2 & $43-M$ & $\begin{array}{l}\text { Ensino médio } \\
\text { (incomp.) }\end{array}$ & $\begin{array}{l}\text { Transição } \\
\text { orgânica. Gado e } \\
\text { hortaliças }\end{array}$ & $\begin{array}{l}\text { Origem Paraná. } \\
\text { rural. Assentado } \\
\text { há oito anos. }\end{array}$ & $\begin{array}{l}\text { Apiaí (alto } \\
\text { vale) }\end{array}$ \\
\hline 3 & $62-M$ & $\begin{array}{l}\text { Fundamental } \\
\text { (incomp.) }\end{array}$ & $\begin{array}{l}\text { Reconversão para } \\
\text { o sistema } \\
\text { convencional de } \\
\text { tomate, hortaliças } \\
\text { e gado }\end{array}$ & $\begin{array}{l}\text { Origem em } \\
\text { quilombo no } \\
\text { Vale do Ribeira. }\end{array}$ & $\begin{array}{l}\text { Barra do } \\
\text { Chapéu (alto } \\
\text { vale) }\end{array}$ \\
\hline 4 & $56-M$ & $\begin{array}{l}\text { Fundamental } \\
\text { (incomp.) }\end{array}$ & $\begin{array}{l}\text { Agricultura } \\
\text { tradicional de } \\
\text { arroz. Pupunha e } \\
\text { hortaliças } \\
\text { orgânicas. }\end{array}$ & $\begin{array}{l}\text { Origem do sul } \\
\text { do Paraná. } \\
\text { Rural }\end{array}$ & $\begin{array}{l}\text { Cananéia } \\
\text { (baixo vale) }\end{array}$ \\
\hline 5 & $55-\mathrm{M}$ & $\begin{array}{l}\text { Superior } \\
\text { (incomp.) }\end{array}$ & $\begin{array}{l}\text { Curta experiência } \\
\text { em agricultura } \\
\text { orgânica. Produtor } \\
\text { de banana } \\
\text { convencional }\end{array}$ & $\begin{array}{l}\text { Origem: família } \\
\text { rural a muitas } \\
\text { gerações no } \\
\text { local. }\end{array}$ & $\begin{array}{l}\text { Sete Barras } \\
\text { (médio vale) }\end{array}$ \\
\hline 6 & $27-M$ & $\begin{array}{l}\text { Ensino médio } \\
\text { técnico }\end{array}$ & $\begin{array}{l}\text { Produtor de gado, } \\
\text { subsistência } \\
\text { convencional e } \\
\text { diarista (resina) }\end{array}$ & $\begin{array}{l}\text { Origem: cinco } \\
\text { Gerações local }\end{array}$ & $\begin{array}{l}\text { Barra do } \\
\text { Chapéu (alto } \\
\text { vale) }\end{array}$ \\
\hline 7 & $54-\mathrm{M}$ & $\begin{array}{l}\text { Fundamental } \\
\text { (incomp.) }\end{array}$ & $\begin{array}{l}\text { Agricultura } \\
\text { convencional. } \\
\text { Transição } \\
\text { orgânica pupunha } \\
\text { e arroz. } \\
\end{array}$ & $\begin{array}{l}\text { Origem: local. } \\
\text { Agricultores } \\
\text { tradicionais }\end{array}$ & $\begin{array}{l}\text { Cananéia } \\
\text { (baixo vale) }\end{array}$ \\
\hline 8 & $63-M$ & $\begin{array}{l}\text { Fundamental } \\
\text { (incomp). }\end{array}$ & $\begin{array}{l}\text { Agricultor } \\
\text { tradicional. } \\
\text { Transição } \\
\text { orgânica. }\end{array}$ & $\begin{array}{l}\text { Origem: local } \\
\text { Família } \\
\text { encontra-se há } \\
\text { gerações no } \\
\text { local. }\end{array}$ & $\begin{array}{l}\text { Cananéia } \\
\text { (baixo vale) }\end{array}$ \\
\hline 9 & $47-F$ & $\begin{array}{l}\text { Superior } \\
\text { (incomp) }\end{array}$ & $\begin{array}{l}\text { Agricultor } \\
\text { tradicional. Depois } \\
\text { tomate } \\
\text { convencional } \\
\text { Transição } \\
\text { orgânica amoras } \\
\text { pretas. }\end{array}$ & $\begin{array}{l}\text { Origem: rural. } \\
\text { Exerce cargo } \\
\text { político há oito } \\
\text { anos no } \\
\text { município.de um } \\
\text { ano). }\end{array}$ & $\begin{array}{l}\text { Barra do } \\
\text { Chapéu (alto } \\
\text { vale) }\end{array}$ \\
\hline
\end{tabular}

Fonte: Dados oriundos da pesquisa de campo (2017), conduzida pelos autores 
Os Quadros 2 e 3, mostram que os entrevistados possuem uma diversidade alta com relação à idade. Variando de uma faixa etária de 27 anos (mais jovem) aos 63 anos (mais velho). Existe a predominância de pessoas do sexo masculino, sendo que entre os agricultores há sete homens e duas mulheres, e entre os técnicos dois homens. A escolaridade também é variada, sendo menor entre os três agricultores do Baixo Vale. Todos entrevistados possuem apenas o ensino fundamental incompleto.

Por outro lado, observou-se que a experiência técnica desses agricultores é rica e diversa. Todos relatam que o principal aprendizado foi adquirido com os pais. Alguns afirmam também que a formação técnica contribuiu sobremaneira para ampliar a experiência deles. Com exceção de um agricultor que atua no Alto Vale, todos tiveram experiência com produção orgânica, sendo que sete deles ainda permanecem desenvolvendo esse tipo de manejo.

$\mathrm{Na}$ trajetória dos agricultores destaca-se a experiência com cultivo convencional, observada em todos os entrevistados. Os agricultores que produzem de forma orgânica afirmam que a experiência de ter produzido de forma convencional os sensibilizou para os riscos desse tipo de produção e os motivou a transição para o sistema orgânico de produção e, consequente possibilitou a permanência na unidade de produção. Dos nove agricultores entrevistados, quatro complementam a renda com trabalho externo. Dentre os tipos de trabalhos externos que eles executam encontram-se o de venda de diárias executando serviços agrícolas, trabalhos na construção civil e exercício de cargo político. Os outros três agricultores obtêm a renda somente da agricultura, não exercendo nenhuma outra atividade extra. Todos os agricultores têm laços muito fortes com suas comunidades. Dos nove, somente três são naturais de outros estados. Dois deles estão a mais de 30 anos na região, e um a 10 anos.

Todos os agricultores entrevistados participam de associação, cooperativa, sindicato ou ambos. Além disso, um deles participa do conselho municipal de desenvolvimento rural (Médio Vale) e os três agricultores do Baixo Vale participam do conselho do Parque Estadual do Lagamar de Cananéia que está no entorno da comunidade.

\subsection{TIPOLOGIA DOS SISTEMAS DE PRODUÇÃO}

Neste tópico apresenta-se a caracterização das unidades de produção agrícola através de suas dimensões produtivas: tipo de culturas, práticas e emprego de técnicas em relação com a natureza. Essa apresentação se justifica uma vez que para o agricultor a definição de estratégias específicas apropriadas à realização do seu projeto pessoal e familiar, dependerá da interação dos níveis de realidade material e de condições objetivas para a produção (ABREU, 2005).

Os diferentes sistemas identificados:

1) Sistema agroflorestal diverso - (SAF) praticado com maior frequência no médio Vale, mas também foi encontrado no baixo Vale do Ribeira, é caracterizado pela alta presença de espécies vegetais e biodiversidade forte, apresenta uma ou mais espécies de interesse econômico, mas principalmente a banana e o palmito pupunha;

2) Sistema tradicional coivara - (STC) caracterizada pelo manejo de corte e queimada, ocorre no baixo e médio Vale do Ribeira, os principais cultivos são o arroz, feijão, milho e raízes. Vem sendo pouco usado devido às restrições impostas pelas leis ambientais;

3) Sistema de produção de hortaliças - (SPH) típica do alto Vale do Ribeira, e a produção do tomate convencional é o principal cultivo, mas apresenta 
alta variabilidade de produtos entre as áreas de produção dos agricultores, entre folhosas, legumes e algumas frutas. Independente do tipo de manejo convencional ou orgânico;

4) Sistema de bananicultura - (SBA) monocultivo de banana, encontra-se no manejo convencional ou orgânico;

5) Sistema de produção de palmito pupunha - (SPP) monocultivo de palmito pupunha, em manejo convencional ou orgânico.

Quanto aos sistemas de produção convencional ou orgânico, apresenta-se a seguinte divisão: quatro agricultores em manejo de produção orgânica de toda área cultivada, quatro agricultores com o manejo de produção convencional de toda área cultivada e, um agricultor com ambas as formas de produção em cultivo paralelo. Do grupo de orgânicos, apenas dois são certificados pela modalidade Organismo de Controle Social (OCS) e um do grupo por auditoria.

\subsection{PERCEPÇÃO DE AGRICULTORES E TÉCNICOS SOBRE O PAA E O PNAE.}

Uma questão inicial importante no âmbito da discussão da percepção dos agricultores e técnicos sobre o PAA e PNAE, foi a identificação dos tipos de programas (PAA e PNAE) acessados pelos agricultores entrevistados.

Dos nove agricultores entrevistados, apenas dois do Médio Vale do Ribeira, acessaram os dois programas. Dos quatro agricultores do Alto Vale do Ribeira, três acessaram o PAA e, um deles não acessou nenhuma política de mercado institucional. Os três agricultores do Baixo Vale do Ribeira, acessaram apenas o PNAE. A tendência é o acesso majoritário em grupo, pois é incentivado na própria regulamentação dos programas. Entre os agricultores entrevistados somente o grupo do Baixo Vale acessou como grupo informal, operando as notas fiscais individualmente. Mas, na prática a organização prévia e operacionalização dos programas (entregas, processamento e a assistência técnica) ocorreu de forma coletiva, através da interação entre agricultores e técnicos.

Foi apontado como ponto positivo por todos entrevistados, o aumento da renda familiar, proporcionado pela adesão à política do mercado institucional. Os agricultores destacaram como ponto negativo (por quatro deles) a insuficiência das cotas pagas pelos programas. Já entre os técnicos, os valores foram considerados adequados. Foi referido por técnicos que a limitação de valores para uma renda adequada, tem como ponto crucial o fato de que muitos agricultores que acessam o PAA, não conseguem acessar o PNAE, esse último, proporciona uma renda maior. Consideram que a experiência com o PAA deveria ter favorecido os agricultores no processo de aquisição de conhecimento sobre o funcionamento operacional dos programas. Esse conhecimento os conduziriam naturalmente ao PNAE. Esse último, é o programa de mercado institucional mais exigente, especialmente, com relação à qualidade dos produtos, logística de entregas, mas, também é o programa que melhor remunera o agricultor, contudo, a experiência anterior (PAA) não capacitou o agricultor. 
Outro aspecto de destaque identificado nas entrevistas conduzidas com o grupo de agricultores, mas com duas exceções, foi a incompreensão geral sobre o modo de funcionamento dos programas. A maioria não entende como os programas operam a compra direta, os processos, quem é o comprador, os caminhos para o recebimento dos valores comercializados. Isso não se diferenciou tendo o agricultor acessado o programa ou não. Exceto dois agricultores que acessaram os dois programas e trabalharam diretamente na sua operacionalização, o restante do grupo não sabia explicar os objetivos e como funcionavam os programas, o significado das siglas dos programas. Essa tendência não foi observada entre os agricultores que exercem cargos de direção de associações e de cooperativas e entre técnicos que atuam com o mercado institucional.

No que diz respeito à compreensão dos programas, os técnicos relatam que alguns agricultores passam a entender o funcionamento dos programas, a partir do momento em que vão assumindo as tarefas e dominando a parte burocrática dos programas. Nesses casos, os agricultores afirmam que os programas geram habilidades, as quais os agricultores não detinham, antes da experiência de comercialização no mercado institucional, que ocorre não só com relação à administração da parte documental, mas também com relação à logística, embalagem e qualidade de produtos.

...Precisavam de muita ajuda, muita paciência, muito papel de pão com produto anotado, muito produto sem pesar. O PAA foi didático nesse sentido, foi com o PAA que as comunidades aprenderam a pesar produto, a contar, anotar, ter controle, e ter algum padrão de qualidade, o padrão era adequado para consumo..." (Técnico F. V.).

Mas tal fato não pode ser generalizado pois as funções permanecem sendo realizada por técnicos, situação encontrada no grupo do Baixo Vale. Porém, os técnicos apontaram que ainda existem um número significativo de agricultores, na região estudada, que nem sequer tem conhecimento da existência desses programas e que no geral, mesmo os que acessaram não entendem claramente em que consiste e, como funcionam os programas. Foi observado que o alcance dos programas foi limitado com relação ao universo quantitativo da agricultura familiar na região. Ou seja, a quantidade de famílias de agricultores que acessaram um dos programas PAA ou PNAE, ou ambos, em algum momento, quando confrontadas pelos dados do Censo 2006 é pouco significativo. O Quadro 4 apresenta os dados quantitativos de agricultores e a estimativa de acesso aos programas no Vale do Ribeira.

Quadro 4 - Total de agricultores e estimativa de acesso.

\begin{tabular}{|l|c|c|c|}
\hline Município & $\begin{array}{c}\text { № de } \\
\text { estabelecimentos } \\
\text { da agricultura } \\
\text { familiar }^{*}\end{array}$ & $\begin{array}{c}\text { № estimado de } \\
\text { famílias que } \\
\text { acessaram um } \\
\text { dos programas }\end{array}$ & $\begin{array}{c}\text { \% estimada de } \\
\text { acesso com } \\
\text { relação ao total } \\
\text { de famílias }\end{array}$ \\
\hline Apiaí & 314 & 120 & 38,2 \\
\hline Barra do Chapéu & 367 & 10 & 2,7 \\
\hline Eldorado & 864 & 200 & 23,1 \\
\hline Sete Barras & 590 & 70 & 11,8 \\
\hline Cananéia & $7^{* * *}$ & 12 & - \\
\hline
\end{tabular}

Fonte: Dados do Censo, 2006* (coluna 1). Pesquisa de campo, 2017 ${ }^{\star \star}\left(\right.$ coluna 2) ${ }^{3}$.

\footnotetext{
${ }^{3} \mathrm{~A}$ informação de Cananéia, no Censo de 2006, apresenta um erro de digitação, pois durante a pesquisa de campo foi identificado mais de 100 estabelecimentos da agricultura familiar no município***.
} 
Mesmo no município de Apiaí, onde o número de estabelecimentos é expressivo, foi observado que os agricultores acessaram os programas por apenas dois anos, mas não conseguiram aprovar novos projetos, nas últimas chamadas dos programas. Isso também ocorreu entre os agricultores de Cananéia e Barra do Chapéu. O depoimento de um técnico:

\begin{abstract}
...A política pública, ela tem que seguir um arrasto, uma coisa tipo arrastão, vem fazendo geral. Não dá para ser uma coisa ....aqui, um caso aqui, outro ali, isso não funciona. É muito mais fácil você perder aquele caso, pois você não cria uma massa crítica para isso, um movimento para isso. Pensando em termos até de atuação de mercado, existe o mercado institucional que é muito forte, e eu sinto que os programas fizeram que o agricultor acessasse, mas basicamente só beliscar (Técnico D. F. J.).
\end{abstract}

Foi indicado como aspecto muito importante pelo conjunto dos agricultores à assistência técnica, até por àqueles (agricultores) do Alto Vale, que acessaram o PAA sem qualquer tipo de assistência técnica. Afirmaram que é crucial o suporte técnico e que sem assistência qualificada (em práticas agroecológicas, aplicadas em sistemas orgânicos ou agroflorestais) seria inviável operar os programas. Os agricultores do Baixo Vale destacaram que se não fosse o trabalho de assistência denominado "Cooperação Técnica", realizada por uma associação de técnicos da região, qualificados em agroecologia, eles não teriam acessado o PNAE.

\begin{abstract}
...Apesar de que vocês (técnicos) estão dando a cara às tapas também para ajudar nós, porque senão nós não ia também conseguir, porque se deixasse para nós correr atrás do jeito que já estamos desacorçoados nós não vamos. Fomos porque vocês estavam juntos né." (Agricultor F. A.).
\end{abstract}

Os dois agricultores do Médio Vale foram acompanhados pela "Cooperação Técnica". Segundo esses agricultores esse suporte possibilitou muitas melhorias na produção, principalmente na produção orgânica. A importância do trabalho técnico foi apontada por Sabourin (2017), afirmando que nenhuma política pública, embora socialmente construída e legitimada, pode ser institucionalizada sem contar com um conteúdo técnico e instrumental robusto.

Os agricultores do Baixo e do Médio Vale afirmaram que a assistência técnica qualificada possibilitou acessar os programas com produtos orgânicos, o que gerou melhor remuneração. A respeito do acesso aos programas do mercado institucional através da produção orgânica, os técnicos afirmaram que o aporte de até $30 \%$ no valor das mercadorias orgânicas atua como um estímulo à produção. Isso ocorreu com os agricultores entrevistados no Médio e no Baixo Vale, nesses locais a produção orgânica expandiu em função dos programas.

Outro impacto positivo dos programas observado nos locais foi a emergência do processo de indução da legalização documental das terras dos agricultores, aspecto apontado por técnicos e agricultores, além da constatação in lócus. No caso do Baixo Vale, que sofre com dificuldades estruturais devido à falta de apoio do poder público para o acesso aos programas de mercado institucional, esse impacto foi extremamente importante. Os agricultores do local, devido ao acesso ao PNAE, foram "forçados" a regularizar toda a documentação que eles não possuíam e era uma exigência obrigatória para adesão ao programa de compras 
institucionais. Os documentos obtidos por eles foram, DAP's, Nota Fiscal de Produtor, Imposto Territorial Rural (ITR) e para alguns agricultores até as declarações de posse da terra e a regularização do Cadastro de Pessoa Física (CPF), que estavam inativos. No caso dos agricultores do Médio Vale, a institucionalização de mecanismos de certificação orgânica, os levaram para a produção orgânica.

No geral os agricultores apresentam percepções semelhantes com relação aos impactos observados, ainda que as condições socioeconômicas, os tipos de sistemas produtivos e os programas acessados sejam diferentes. Dentre os impactos observados que se constitui em percepções diferenciadas entre os agricultores, está o valor da cota dos produtos comercializados. Chama atenção a justificativa dos agricultores que consideram o valor baixo, mas isso não se encontra associado diretamente ao preço, mas a incapacidade do programa absorver o volume produzido. Esses agricultores afirmam sentir frustração quando não conseguem comercializar a totalidade da produção.

\section{CONSIDERAÇÕES FINAIS}

$\mathrm{O}$ artigo apresentou o conjunto de aspectos associados às percepções de atores chaves (produtores e técnicos) sobre o PAA e PNAE e caracterizou seus impactos positivos e negativos, de modo geral os programas contribuíram para o aumento da renda familiar dos agricultores que acessaram os programas. A questão da melhoria da renda é o ponto de interesse comum entre os agricultores mesmo em situações socioeconômicas, ambientais e produtivas diferentes. Sem esquecer que a inserção nos programas potencializou o acesso à assistência técnica. Outro impacto positivo observado foi o estímulo à regularização documental dos agricultores, este aspecto mostrou capaz de impulsionar o acesso desses agricultores à política pública.

Também em relação à aquisição de novas habilidades técnicas associadas aos procedimentos operacionais dos programas foi constatado em parte do universo da pesquisa, a apropriação de novos conhecimentos e práticas de processamento dos alimentos, escoamento ou ambos. Essas novas capacidades se mostraram dependentes de assistência técnica, e em alguns casos, permaneceram sendo praticadas independente dos programas.

O estímulo à transição e à produção orgânica é um impacto positivo que deve ser destacado, porém, mostrou-se também, dependente de acompanhamento. Há forte dificuldade por parte dos agricultores com relação à falta de conhecimentos em técnicas de produção orgânica e ainda sobre os mecanismos de garantia e certificação dessa produção. Essa dependência de assistência técnica foi um ponto levantado pelos atores da pesquisa que mostram claramente os limites dos programas e, a necessidade de solução desse gargalo. A assistência dever ter capacidade de atender às questões de ordem agronômica, mas de natureza agroecológica, administrativas, logísticas e de relações institucionais para maior efetividade no auxílio à execução dos programas.

A incompreensão da operacionalização dos programas pela maioria dos agricultores é um ponto observado em diferentes graus, mas presente e, reafirmado pelos técnicos como fato mais amplo. Os agricultores não compreendem a estrutura institucional das políticas públicas e o histórico político institucional ocorrido até o reconhecimento e institucionalização da política pública do mercado institucional. Além disso, a operação é compreendida de maneira geral pelos agricultores, como uma ação que depende de indivíduos, lideranças ou de diretores de suas instituições. Isso tira o caráter de direito da política e a torna em alguns casos, como 
uma ferramenta de barganha política local e regional. Novamente um trabalho técnico se põe como um dos caminhos que pode ser o disseminador de informações claras das regras e funcionamento dos programas, gerando a autonomia que se espera como resultado das políticas.

Os programas tiveram acertos e falhas nos territórios selecionados da região do Vale do Ribeira (SP). No entanto, ao não ter incluído o universo da agricultura familiar de forma abrangente, marginalizou parte dos agricultores familiares presentes na região.

Portanto, ajustes são necessários, os quais em essência dizem respeito aos seguintes aspectos dos programas: treinamento de assistência técnica adequada e capaz de interagir com as diversas instâncias do setor público e organizações da sociedade civil; revisão dos mecanismos que favoreçam a garantia do cumprimento da lei do PNAE, por parte dos municípios, estados e união, garantindo a compra de no mínimo de $30 \%$ da alimentação escolar da agricultura familiar; e melhorias na gestão e no monitoramento e fiscalização da operação dos programas.

Por último, é necessário ainda aprofundar o conhecimento, em algumas questões investigadas, especialmente em relação ao processo de transição agroecológica e ao papel do Estado na construção de um novo modelo de assistência que assegure o sucesso das políticas públicas.

\section{REFERÊNCIAS}

ABREU, L. S. A construção da relação social com o meio ambiente entre agricultores familiares da mata atlântica brasileira. Jaguariúna: Embrapa Meio Ambiente, 2005.

ABREU, L. S. et al. Relações entre agricultura orgânica e agroecologia: desafios atuais em torno dos princípios da agroecologia. Desenvolvimento e Meio Ambiente, Curitiba, v. 26, p. 143-160, 2012.

ALTIERI, M. Agroecologia: bases científicas para uma agricultura sustentável. Guaíba: Agropecuária, 1995.

BRASIL. Casa Civil. Lei Federal no 11.947, de 16 de junho de 2009. Disponível em: http://www.planalto.gov.br/ccivil_03/_ato2007-2010/2009/lei/111947.htm. Acesso em 23 out. 2018.

BRASIL. MDS. O Programa de Aquisição de Alimentos - PAA. Disponível em: http://mds.gov.br/assuntos/seguranca-alimentar/programa-de-aquisicao-dealimentos-paa. Acesso em 23 out. 2018.

BRASIL. FNDE. Resolução CD/FNDE no 04/2015. Disponível: http://www.fnde.gov.br/arquivos/category/116alimentacaoescolar?download=9815: pnaemanual-aquisicao-de-produtos-da-agricultura-familiar-para-a-alimentacaoescolar-2. Acesso em 23 out. 2018.

CAZELLA, A, A.; MATTEI, L.; SCHNEIDER, S. Histórico, caracterização e dinâmica recente do PRONAF. Porto Alegre, Rio Grande do Sul, 2004.

COHEN, E; FRANCO, R. Avaliação de projetos sociais. São Paulo: Vozes, 1993. 
CONAB. Companhia Nacional de Abastecimento. Agricultura familiar. Brasília, 2013 Disponível em: http://www.conab.gov.br/conteudos. pupa=1125\&t=2. Acesso em 15 nov. 2018.

FUNDAÇÃO SEADE. Perfil Municipal 2013. Acesso em 20/10/2017. Disponível em: http://www.seade.gov.br/produtos/perfil/

IBGE. Censo Agropecuário 2006: Agricultura Familiar - Primeiros Resultados. Brasil, Grandes Regiões e Unidades da Federação. Censo Agropecuário. Rio de Janeiro, p.1-267, 2006.

IBGE. Censo Demográfico 2010: característica das populações e dos domicílios. Censo demográfico, Rio de Janeiro, p.1-270, 2010.

ISA. Instituto Socioambiental. Agenda socioambiental de comunidades quilombolas do Vale do Ribeira. Editores Kátia M. Pacheco dos Santos, Nilton Tatto, 2008.

LAMARCHE, H. (Coord.). A agricultura familiar, do mito à realidade. Campinas; Editora da Unicamp. v. 2. 1998.

KAUFMANN, M. PRISCILA; PASQUALOTTO, N.; SENA, M. MACHADO. A Construção do conhecimento agroecológico no território central do Rio Grande do Sul. uma experiência baseada na metodologia campesino a campesino. Extensão Rural, Santa Maria, v.26, n.3, p.7-20, jul./set. 2019. Disponível em: https://periodicos.ufsm.br/extensaorural/article/view/39859/pdf. Acesso em: 12 nov. 2019.

MATTEI, L. O papel e a importância da agricultura familiar no desenvolvimento rural brasileiro contemporâneo. Rev. Econ. NE, Fortaleza, v. 45, p. 71-79, 2014.

PNUD. Programa das Nações Unidas para o Desenvolvimento. Relatório do Desenvolvimento Humano 2011. Sustentabilidade e Equidade: um futuro melhor para todos. Washington: PNUD, 2011. 183p.

ROBRAHN-GONZÁLEZ, E.M.; BLASIS, P. Investigações arqueológicas no médio/ baixo vale do Ribeira de Iguape, São Paulo. Rev. do Museu de Arqueologia e Etnologia, São Paulo, v. 8, 57-69, 1998.

SABOURIN, E. Origens, evolução e institucionalização da política de agricultura familiar no Brasil. In: DELGADO, G. C.; BERGAMASCO, S. M. P. P. (ORGs). Agricultura familiar brasileira: desafios e perspectivas de futuro. Brasília: Ministério do Desenvolvimento Agrário (MDA), p. 265-291. 2017.

SANTOS, P. K. M; TATOO, N. Agenda socioambiental de comunidades quilombolas do Vale do Ribeira. São Paulo. Instituto Sócio Ambiental. 2008.

SCHIMITT, C. J.; GUIMARÃES, L. A. O mercado institucional como instrumento para o fortalecimento da agricultura familiar de base ecológica. Agriculturas, v. 5, n. 2, jun. 2008. 
VEIGA, J. E. Agricultura familiar e sustentabilidade. Cadernos de Ciência \& Tecnologia, Brasília, v.13, n.3, p.383-404, 1996.

WEBER, M. Metodologia das ciências sociais. Editora Cortez: Universidade Estadual de Campinas. 1999. 